Mkwawa Journal of Education and Development, Vol. 1, Issue 1, 2017

DOI: https://doi.org/10.37759/mjed.2017.1.1.3

\title{
The Swahili Noun Phrase in its Sentential Aspect
}

\author{
Amani Lusekelo ${ }^{1}$
}

\begin{abstract}
This paper articulates the syntactic properties of nouns in Swahili in relation to functional projections which are associated with both concord in determiner phrases and agreement in inflectional phrases. With regards to realisation of syntactic properties in Bantu noun phrases, three claims had been suggested based on different approaches, vis-à-vis the use of pre-prefix to denote discourse-based information about (in)definiteness, indication of phi-features in minimalist syntax by using the nominal prefix, and determination by demonstratives and possessives as supported by head proximity principle. Findings from Swahili texts point towards the fact that bare nouns receive either definite interpretation or indefinite reading depending on the context of communication. Therefore, the definite-indefinite distinction is not provided by physical linguistic materials, but by discourse-based contexts. Even when a demonstrative and/or possessive is used, it is the context of communication which situates the specific referent rather than the lexical entities. Findings indicate that the choice between demonstratives and possessives in determinations of Swahili NPs is also context bound.
\end{abstract}

Keywords: noun phrase; determination; definiteness; word order; Swahili

DOI: https://doi.org/10.37759/mjed.2017.1.1.3

\section{Introduction}

The organisation of the functional domains and lexical elements within a noun phrase is the focus of the present study. Abney (1987) postulated that the head of the noun phrase is the functional element of determiner which manifests in the left-edge of the phrase hence DP. The lexical domain is postulated as being lower than the DP and its projection is from the lexical-noun into an NP. This is assumed to be possible in a language whose grammar permits manifestations of the (in)definite articles such as a/the in English, une/la in French, un/il in Italian, etc. (Alexiadou, Haegemann \& Stavrou, 2007). For a language whose grammar does not make use of (in)definite articles, the projection of the $\mathrm{D}$ is designed to emanate from a discourse-based information about (in)definiteness which indeed subsumes into the determiner slot (Szabolczi, 1994; Mojapelo, 2007).

In languages without (in) definite markers such as Swahili and other Bantu languages, three analytical postulations emanate from DP hypothesis. Firstly, the syntactic analysis which has to do with discourse-based information will posit that (in)definiteness is brought about by the use of pre-prefixes in Bantu languages such as Dzamba, isiXhosa, Luganda and Nyakore-Kiiga (Bokamba, 1971; Hyman \& Katamba 1993; Visser, 2010; Allen, 2014). Some syntacticians (e.g., Contini-Morava, 2000; Letsholo, 2004; Henderson, 2006;

${ }^{1}$ Department of Languages and Literature; Dar es Salaam University College of Education; P. O. Box 2329 Dar es Salaam; alusekelo@duce.ac.tz 
Lusekelo, 2013) hypothesise that in Bantu languages without pre-prefixes (e.g., Swahili, Ikalanga, Matengo, Bembe, etc.) the nominal prefix and subject marker share syntactic properties such as phi-features gender, person and number. It is argued that the nominal prefix is paramount in realisations of syntactic properties, but mainly number (ContiniMorava, 2000). Nonetheless, the latter claim is questioned by other scholars (e.g., Ndomba, 2006; Rugemalira, 2007; Iori, 2011) who lean their ideas on head proximity principle which warrants demonstratives and possessives to occur adjacent to the lexical-head. Given this scenario, the purpose of the current study is to challenge all these three postulations and suggest an alternative approach to the syntax of the Bantu noun phrase with special reference to Swahili.

\section{The review of the syntactic issues in Bantu $D P^{2}$ from literature}

The postulation of the DP hypothesis has created an interesting debate about the structure of the noun phrases in Bantu languages. The debate surrounds the concatenation of morphosyntactic units around a lexical noun. In fact, the morphology and syntax of Bantu nouns permit three elements to co-occur within it, namely: a pre-prefix, noun class prefix and the lexical-root of the noun. These constituents embrace a number of syntactic issues related to Abney's (1987) DP hypothesis. As such, these units have led into the formation of three camps which argue in support of a given syntactic phenomenon.

The first group of scholars (e.g., De Blois, 1970; Bokamba 1971; Hyman \& Katamba 1993; Mojapelo, 2007; Visser, 2010; Allen, 2014, among others) assume that matters related to (in)definiteness in Bantu languages are conveyed by the pre-prefix, which manifests in the left-edge of the noun phrase, as illustrated in the following examples:

$$
\begin{aligned}
& \text { Mo-ibi anyoloki } \quad \text { o-ndaki } \\
& \text { 1-thief entered Adamba, Bokamba 1971, p.220] } \\
& \text { 'A thief entered the house.' }
\end{aligned}
$$

$$
\begin{array}{lll}
\text { O-mo-ibi } & \text { anyoloki } & \text { o-ndaki } \\
\text { AU-1-thief } & \text { entered } & \text { AU-9.house }
\end{array}
$$

'The thief entered the house.'

I-ntombi a-zi-yi-hlambi ngubo [isiXhosa, Visser 2010, p.302]

AU-10.girl NEG-SM10-PRES-9-wash 9.blanket

'The girls do not wash any (not specific) blanket.'
I-ntombi a-zi-yi-hlambi
i-ngubo

AU-10.girl NEG-SM10-PRES-9-wash AU-9.blanket

'The girls do not wash the (specific) blanket.'

\footnotetext{
${ }^{2}$ Abbreviations: ADJ: adjective, ASSOC: associative (genitive) marker, AU: (augment) or preprefix, DEM: demonstrative, FV: (default) final vowel, INF: infinitive (form), NEG: negation marker, NUM: numeral, OM: object marker, PFV: perfective (aspect), PL: plural, POSS: possessive, PRES: present (tense), PST: past (tense), QUANT: quantifier, SG: singular, SM: subject marker, 12 3 etc.: nominal classes, and (-): morpheme boundary.
} 
Bokamba (1971) and Visser (2010) found that unaugumented noun phrases moibi 'a thief' in Dzamba (example 1) and ngubo 'a blanket' in isiXhosa (example 3) provide indefinite interpretations. The opposite is true because manifestations of the pre-prefixes in omoibi 'the thief' (example 2) and ingubo 'the blanket' (example 4) in these languages are associated with definite interpretations. In this camp, the D is assumed to be a projection emanating from the pre-prefix; hence, we obtain the following tree diagram:

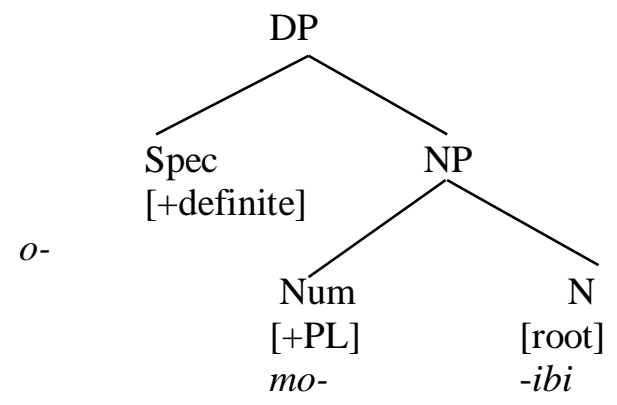

One bottleneck remains from the postulation provided above. Many Bantu languages do not have pre-prefixes. With reference to Maho (1999), noun phrases of many Bantu languages do not manifest. Similarly; Matengo, Meru and Swahili noun phrases do not manifest with the augment (Ndomba, 2006; Contini-Morava, 2000; Lusekelo, 2009a; Sarakikya, 2016). Given this scenario, it follows that one main question remains for Bantu languages whose grammars do not permit pre-prefixes: "how does (in)definiteness get realized in a sentence?"

The second group of scholars (e.g., Carstens, 1991; Contini-Morava, 2000; Letsholo, 2004; Henderson, 2006; Lusekelo, 2013, among others) tries to answer this question. These scholars suggest that apart from the pre-prefix, the nominal prefix embraces the phi-feature number (as well as person and gender). Thus, the nominal prefix is paramount in the control of the concord within noun phrases and agreement between the noun phrase and verb phrase. This suggestion is plausible because Bantu languages lack (in) definite articles. The syntactic power of the phi-feature number in Bantu languages is illustrated by the following examples:

$\begin{array}{lllll}\text { (6) } & \text { Wa-toto } \boldsymbol{w a} \text {-le } \boldsymbol{w a} \text {-na-cheza } & \text { m-pira } & \text { [Swahili, Lusekelo 2013, } \\ \text { p.43] } & & & \\ & \text { 2-child 2-those SM2-PRES-play-FV } & \text { 3-ball }\end{array}$

$$
\begin{array}{lll}
\text { Neo } & \text { wa-ka-bon-a } & \text { mbisana } \\
\text { 1.Neo } & \text { SM1-PST-see-FV } & 1 . \text { boy }
\end{array}
$$

Based on minimalist approach to syntax, it is suggested that both common and proper nouns interact with the verbal complexes in realisations of phi-features. In (6) the concord within the noun phrase is realised by the marker $w a$ - which is manifested in the common noun 


\section{Mkwawa Journal of Education and Development, Vol. 1, Issue 1, 2017 DOI: https://doi.org/10.37759/mjed.2017.1.1.3}

watoto 'children' and the dependent wale 'those'. Also, this example demonstrates how 'agreement between the verb and subject is obligatory in finite sentences' (Letsholo, 2004, p.105). The subject marker $w a$ - shares syntactic properties, i.e., phi-features number and third person, with the inflectional phrase as it manifests in the verbal complex. Likewise, the agreement marker $w a$ - in example (7) shows the agreement between the subject NP, i.e., the proper name Neo and the verb complex. The subject NP shares phi-features with the subject marker attached to the verb. On the basis of Carstens' (1991) analysis, since the syntactic feature number is paramount in this kind of analysis, the tree in (8) is its representation.

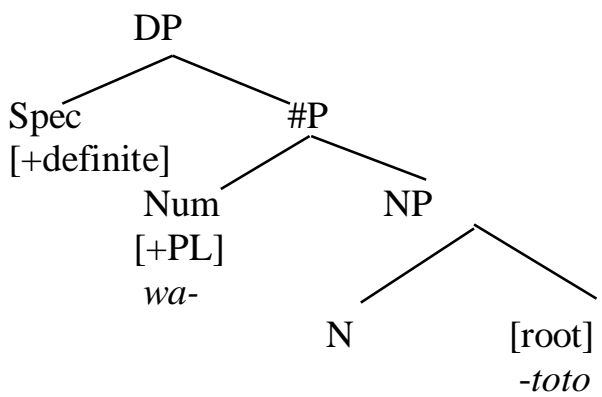

This answer does not satisfy the need to explain how (in) definiteness is demonstrated by nominal prefixes. Many scholars (Hyman \& Katamba, 1993; Petzell, 2008; Lusekelo, 2013; Allen 2014) argue that definiteness and indefiniteness distinction in Bantu languages is not really straightforward. There are cases associated with augments, yet we obtain indefinite interpretations. Also, there are many cases in which definite reading is provided without reference to augments. Probably, the role of lexical elements such as the deictic demonstratives might address this question properly.

There are Bantuists (e.g., Ndomba, 2006; Mojapelo, 2007; Rugemalira, 2007; Magashi, 2008; Lusekelo, 2009a; Jaffu, 2010; Iori, 2011; Chipeta, 2016, among others) who suggest that determination in Bantu languages is the function of lexical elements mainly demonstratives and possessives. Based on the head proximity principle (Rijkhoff, 1986), demonstratives and possessives assume the position adjacent to the head-nouns in Bantu languages. Nonetheless, there are debating camps on this suggestion as follows:

Firstly, the debate may involve a single language. For instance, Magashi (2008) found that only possessives become determiners because they occupy a slot adjacent to the head-noun. This is the case of Sukuma example in (9). The possessive element ßane 'my' occurs adjacent to the noun aßaana 'children'; hence, it qualifies to be the determiner.

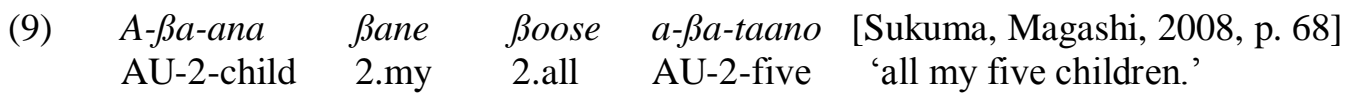

Contrary to Magashi (2008), another researcher (Chipeta 2016) found that both demonstratives and possessives co-occur in the order N > POSS > DEM, as ashown in (10). This implies that both possessives and demonstratives are determiners.

$$
\text { A-ma-ndege ging'we aya ga-ßol-ileSukuma, Chipeta, 2016, p.60] }
$$




\section{AU-6-maize POSS.your DEM.these SM.PL-rot-PERF}

'These maize of yours are rotten.'

Secondly, the debate may involve constituents such as possessives and demonstratives. Inthis manner, some Bantuists such as Mojapelo (2007) and Allen (2014) argue that the deictic element called demonstratives become determiners in Bantu languages. This is the case of the Northern Sotho example in (11) whereby the demonstrative akhwi 'this' provides definite interpretation of the noun maswi 'milk'.
(11) Ma-swi akhwi a a-fiša
6-milk 6.this be 6-hot
[N. Sotho, Mojapelo 2007, p.97]
'This milk is hot.'

This is further supported by the evidence that the demonstrative can precede the lexical noun in a noun phrase. Many Bantu languages permit the demonstrative to occur in the pronominal position (Van de Velde, 2005). Based on the left-periphery hypothesis (Rizzi, 1997), important functional information is housed in the left edge of the phrase in S-V-O languages such as Northern Sotho and Swahili. This is further evidenced by Bembe example in (12) in which the demonstrative may also precede every other element in a noun phrase (Iori, 2011).

$$
\begin{array}{lll}
\text { Bi-nu bya-ne } & \text { bi-tabv bi-bele bya-mmilu wa mikyembo [Bembe, Iori } \\
& \text { 2011: 64] } & \\
\text { 8-these 8-my } & \begin{array}{l}
\text { 8-book 8-two 8-black Assoc Mikyembo } \\
\text { 'these two black books of mine about Mikyembo.' }
\end{array}
\end{array}
$$

Other scholars (Ndomba, 2006; Rugemalira, 2007; Lusekelo, 2009a; Jaffu, 2010) postulate that both possessives and demonstratives may become determiners that may co-occur. However, two options are available for their co-occurrence, namely: fusion of the possessive into the noun, as in Swahili example (13) and shifting the demonstrative into the prenominal position, as the case of Makonde example in (14). Other Bantu languages, e.g., Matengo, permit both demonstratives and possessives to co-occur after the lexical noun, as shown in (15).

$$
\begin{aligned}
& \text { W-ana-we hao wa-li-safiri [Swahili: Shaaban Robert] } \\
& \text { 2-child-POSS 2.those SM2-PST-travel } \\
& \text { 'Those children of his travelled.' }
\end{aligned}
$$

$$
\begin{array}{cllll}
\text { a-va-ano va-ana } & \text { va-angu } & \text { va-viili } & \text { va-leehu } & \text { [Makonde, Jaffu, 2010, p.87] } \\
\text { AU-2-these } & \text { 2-child } & \text { 2.my } & \text { 2-two } & \text { 2-tall }
\end{array}
$$

'these two tall children of mine.'

$$
\begin{array}{lllll}
\text { ma-si } & \text { gala } & \text { gangu } & \text { ma-keli } & \text { [Matengo, Ndomba, 2006, p.77] } \\
\text { 6-water } & \text { 6.that } & \text { 6.my } & \text { 6-dirty 'that dirty water of mine' }
\end{array}
$$

Despite the differences, it is crucial to justify that determination in these languages is primarily embraced by possessives as in Sukuma and/or demonstratives as in Matengo. In addition, in some languages the demonstratives and possessives scramble for determiner position; hence, possessives may fuse on lexical-nouns as in Swahili and/or demonstratives 
can shift to the pronominal position as in Makonde and Bembe. Rugemalira (2007, p.147) puts it rightly as 'determiners include possessives and demonstratives, and to ease the competition between them for determiner status, the pre-determiner position is readily available in many languages.' Using Swahili example wale watoto wawili 'those two children', therefore, the tree diagram in (16) illustrates the claim made.

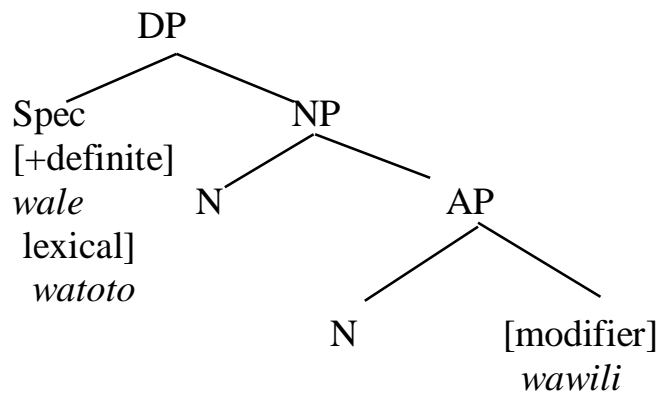

Indeed, the foregoing discussion may leave one with one or more questions unaddressed. For example, in case there are three mechanisms of indication of the D in Bantu noun phrases: what will be the proper way of amalgamating them so as to arrive at the best option fitting all the strategies? An attempt to provide answers for this question was a purpose of this study based on data obtained from Swahili text.

\section{Swahili data: Methodological Issues}

The kind of methodology employed to gather data for current study was 'textual approach' which involves mainly two technical issues vis-à-vis (i) the author's judgmental (critical) ability in deciding about grammaticality of some of the phrases obtained in the Swahili community in Tanzania, and (ii) translation and interpretation of the noun phrases collected by the author from written sources. The decision to use textual materials is supported by resources for linguistic fieldworks (Vaux \& Cooper, 2003; Bowern, 2008) which suggest that texts could be a good source of firsthand information about a linguistic phenomenon.

Specific to textual approach, Bowern $(2008$, p.103) states that, for the purpose of obtaining primary data from natural settings, 'your best clues to constituent order will come from textual data'. This entails that the use of secondary sources such as narrations provide the required information in syntactic analyses. In relation, Vaux and Cooper (2003, p.136) insist that linguists 'must by necessity study the use of language in the real world, which includes not only published texts and recorded narratives, but also elicitations of the grammatical judgments and even introspective reflections on one's own linguistic competence.' This reference underscores the importance of narrations in obtaining natural data. This corroborates a study by Bowern (2008, p.105) who maintains that 'textual data will help to clarify some of these questions and will probably give you yet more puzzles.' It follows, therefore, in this study that, all the tokens of noun phrases were gathered from letters written by Shaaban Robert, as compiled by Mulokozi (2002). The rationale for this choice is twofold. Firstly, the contribution of Shaaban Robert to standard and high-class modern Swahili is outstanding (Blommaert, 2013). His works on Swahili prose (Mulokozi, 1974) and Swahili novels (Zukov, 2004) provide a good ground through which proper Swahili clauses could be gathered and analyzed. Zhukov $(2004$, p.15) states that 'the literary activity by 
Shaaban Robert began when 'Standard Swahili' was under formation and acquiring its fixed form in literary works created by the Europeans and published under their control.' It is Shaaban Robert, 'being an excellent connoisseur and an expert in Kiswahili, he introduced the best features and richness of the folk language and the written literature into 'Standard Swahili'’ (Zhukov, 2004, p.15).

Secondly, it is assumed that the two interlocutors, Shaaban Robert and his brother Yusuf Ulenge, had been communicating about various referents whose knowledge would be known between them. Therefore, the discourse-based information on (in)definiteness would be openly articulated and elaborate. Thirdly, the amount of syntactic information embraced in nominal prefixes and subject agreement markers will also be realized by Shaaban Robert whose writings had been claimed to formulate the basis of standard Swahili (Mulokozi, 2002). Thirdly, combinations of various dependents in complex noun phrases used will throw some light on their proper arrangements. This is in line with Rijkhoff (2002, p.23) who states clearly that 'NPs may vary considerably with respect to their internal organisation and complexity [...] in written language NPs tend to be more complex grammatically than NPs used in spoken language'.

\section{The Analysis of Swahili Noun Phrases}

This section provides insights on the properties of noun phrases in Swahili. It opens up with the characteristics of bare noun phrases. Then it discusses the application of the head proximity principle approach to the analysis of properties of complex noun phrases. Lastly, the section offers mechanisms underpinning determination in Swahili through demonstratives and possessives.

\subsection{Bare Nouns in Swahili Noun Phrases}

A number of syntactic issues emanate from the properties of bare nouns in world languages. The first syntactic matter has to do with the projections of the determiner constituent in 'articleless noun phrases as well as of articleless languages' (Alexiadou et al. 2007, p.52). Swahili is well known as having the property of articleless Bantu languages. Carstens (2008, p.152) qualifies as 'Bantu languages generally lack overt articles.' A question which this study attempts to answer is raised by Alexiadou et al. (2007, p.63) that 'if the article is obligatory for a noun to assume argumental status, how can 'bare' nouns be arguments in languages that have no (definite) article', such as Swahili?

In the existing data from letters of Shaaban Robert, I found that bare nouns are composed of proper names and common nouns. In order to assign the bare nouns as arguments in a clause, the interpretation of the discourse-based information becomes the paramount diagnostics of the (in) definiteness in Swahili. The main indicator of (in) definiteness is not the presence of the articles or the pre-prefixes in Bantu languages without pre-prefixes, but the proper context of communication that defines the situation. Thus, knowledge of the specific referents is obtained in the communications made between Shaaban Robert and Yusuf Ulenge. Also, correspondence on unknown and new referents is conducted between these two interlocutors. Perhaps the following examples will help to substantiate:

$\begin{array}{llll}\text { (17) Wa-nafunzi } & \text { si } & \text { vema } & \text { ku-chelew-a } \\ \text { 2-student } & \text { not } & \text { good } & \text { INF-late-FV }\end{array}$


'Students should not arrive late.'

(18)
Ni-me-pat-a
fedha
SM1-PFV-get-FV 9.money
'I got money.'

Bibi a-me-kuw-am-jamzito

1.Bibi SM1-PFV-be-FV 1-pregnant

'Bibi is pregnant.'
Ali a-me-ach-a
kazi mwezi huи
1. Ali SM1-PFV-leave-FV
'Ali quit the job this month.'
9.job 3-month 3.this

Both common nouns and proper names are used as arguments in the example cases given above. Findings indicate that common nouns used provide indefinite readings. In example (17) the subject NP wanafunzi 'students' provides generic and plural interpretation; hence, indefinite common noun. Shaaban Robert is referring to generic term students as a means to advice his brother, Yusuf Ulenge, on the importance of discipline and respect of regulations (Mulokozi, 2002). Equally important, example (18) has generic common noun fedha 'money' used in the objective case. Therefore, bare common nouns can be used in generic and indefinite format to license both subjective and objective arguments in Swahili.

Proper nouns are also used as arguments in Swahili sentences. Example (19) demonstrates the utilisation of the proper name Bibi, while example (20) makes use of the proper name Ali. It is obvious that reference to these persons is known between the writer of the letters, Shaaban Robert, and the addressee of the letters, Yusuf Ulenge. It is; thus, plausible to argue that proper names used by interlocutors who are aware of the referents provide definite interpretations. This observation is consonant with Mojapelo (2007) who suggests that for the known information, people engaged in communication may refer to such referents using bare nouns.

Another case involves the common noun kazi 'job, work' which is used as objective case in example (20). Here the available interpretation is definite because both Shaaban Robert and Yusuf Ulenge are basically aware of the job/work that the renouncer, i.e., Ali, was employed. Again, given this context of communication, Mojapelo (2007, p.86) argues that 'the physical environment and general knowledge equip the speaker with relevant contexts to express definiteness. The shared environment and knowledge assist the addressee to infer it, as is intended.'

Based on the information provided in the foregoing discussion, I argue that the question of indication of (in) definiteness is a matter of context of communication rather than the physical manifestations of linguistic materials such as definite markers and (in)definite articles. For Swahili, a language without pre-prefixes, context of communication is paramount in deciding whether a given noun, both proper and common names, provides definite or indefinite reading in a clause. Bare nouns, therefore, can function as arguments 
of a verb irrespective of the presence of the (in) definite markers in the language because the context of communication dictates its interpretations.

The first question is now answered as it is argued that neither physical realisations of definiteness by augments nor the role of nominal prefixes could establish the definiteness and indefiniteness readings in bare nouns in Swahili. However, for bare nouns in Swahili, it is the physical environment and the shared knowledge which control the (in) definiteness in Swahili language.

\subsection{Determination by Demonstratives and Possessives}

The structure of the noun phrase is composed of many lexical elements which occupy independent syntactic constituents. Abney (1987) and Rizzi (1997) suggested that the leftperiphery of the phrase constitutes the functional heads. Given the mirror image of English noun phrase, Bantu languages reveal the left-edge of noun phrases which is composed of two elements, the demonstrative and possessive (Rugemalira, 2007; Lusekelo, 2009b). This is in line with Alexiadou et al. (2007, p.94) who suggested that 'its leftmost specifier position was taken to be occupied by a number of different elements such as articles, demonstratives, possessive NPs, possessive adjectives and interrogative pronouns.'

Since the absence of (in)definite markers is assumed to be replaced by demonstratives and possessives, it follows that determinations in Bantu noun phrases could be formulated by these elements. However, we have shown in section 2 e that scholars differ in their postulations of the determiners in Bantu languages. While Magashi (2008) suggests the possessive as the determiner, Mojapelo (2007) and Iori (2011) propose that demonstratives are, indeed, determiners. Furthermore, Rugemalira (2007), Lusekelo (2009a, b) and Jaffu (2010) advocate that both demonstratives and possessives are involved in determination. Therefore, in this study I needed to examine the way Shaaban Robert had been using these elements to indicate the definite nouns in his letters. Perhaps the following examples will help to substantiate his indication of (in)definiteness.

$\begin{array}{lllll}\text { U-si-tumi-e } & \text { vi-tabu } & \text { hivi } & \text { katika } & \text { darasa } \\ \text { SM2-NEG-use-IMPER } & \text { 8-book } & \text { 8.these } & \text { in } & \text { 5.class }\end{array}$

'You should not use these books in class.'

(22) Barua yako i-me-wasili

9.letter 9.your SM9-PFV-arrive

'Your letter arrived.'

(23) Waraka wako na-u-rusish-a

11.letter 11.your SM1-OM11-return-FV

'Your letter, I return.'

The utilisation of both demonstratives and possessives is common in the letters of Shaaban Robert. This means that even for the cases which both interlocutors knew exact referents, these determination words are frequently used. It is now obvious that both demonstratives and possessives are used by Shaaban Robert to indicate definite referents. In example (21), the demonstrative hivi 'these' functions to provide definite interpretation of the noun vitabu 
'books'. In example (22) the possessive yako 'your' gives definite reading the noun barua 'letter'. Even in topicalised NPs, the possessive could be used to provide definite interpretation of the noun, as shown in (23). The topicalised NP waraka wako 'your letter' appears with a possessive so as to realise definiteness.

Based on this assumption, it is suggested in this study that apart from the contributions of the contexts of communication, determination in Swahili is partly realised by the utilisation of demonstratives and possessives. Therefore, the question of indication of exact referents is made possible by the use of lexical elements. These lexical entities require the context of use to be tied to the context of communication. Thus, both the context of use and the lexical word combine to formulate definite interpretations of the Swahili noun phrases.

Nonetheless, we showed in section 2 above that it is possible for grammars of Bantu languages to stack both determiners (i.e., demonstratives and possessives) in one phrase in a clause. This behaviour is also demonstrated in textual sources of data used forthis study. Now, when this happens, then what is it that becomes the primary determiner in Swahili? Based on head-proximity principle (Rijkhoff 1986), this question is answered in the subsequent sub-section.

\subsection{The Head Proximity Principle Approach to Complex Noun Phrases}

In order to examine to know which one is more significant element than the other between demonstratives and possessives in Swahili NPs, head-proximity principle by Rijkhoff (1986) is utilised. In this principle, it is postulated that head-noun is surrounded by term operators (i.e., determiner, quantifier and modifier e.g., adjectives and genitives). Thus, the principle of head proximity states that 'the head of a domain prefers to be contiguous to the head of its superordinate domain' (Rijkhoff, 1986, p.100). The first point to be underscored for this principle is that head nouns reign in the noun phrase and subordinators occur adjacent to the head noun.

According to Rijkhoff (1986, p.118), 'the ordering principles that have been proposed so far' are as 'terms prefer the ordering, which goes as: Operator - N - Adj - Relative clause'. In addition, 'adjectives may pattern along with term operators' and 'genitives may pattern along with adjectives'. It should also be noted that 'term operators typically encode such notions as (in) definiteness and number, which may be expressed formally by determiners and quantifiers/numerals' (Rijkhoff, 1986, p.119). The second point to underline here is that determiners will always occur adjacent to the head noun.

In order to examine the appropriateness and applicability of this principle to the structure of the Swahili noun phrase, e thirty-one tokens of complex NPs were collected from letters of Shaaban Robert and examined for that purpose. The amount of information gathered reflects the suggestions offered in section 4.2 above in that both the context of use and the lexical word combine to formulate definite interpretations of the Swahili noun phrases. This is illustrated by examples (24-28) below. Notice that tokens used in these examples involve complex noun phrases with two dependents. 
Mkwawa Journal of Education and Development, Vol. 1, Issue 1, 2017

DOI: https://doi.org/10.37759/mjed.2017.1.1.3

Hapana neno $\quad$ lolote
there is no baya
'There is no any bad statement'

$\begin{array}{llllll}\text { Ni-me-furahi } & k u \text {-ku-letea } & \text { ki-atu } & k i \text {-dogo } & \text { cha } & \text { ngozi } \\ \text { SM1-PFV-happy } & \text { INF-OM2-bring } & \text { 7-shoe } & \text { 5-small } & \text { 7.Assoc } & \\ \text { 9.leather } & & & & \end{array}$

'I am happy to have brought you a pair of small leather shoes'

(26) Ni-me-pat-a

SM1-PFV-get-FV 10.letter 10.your 10.two

'I got two letters of yours'

$\begin{array}{llllll}\text { Na-fahamu } & \text { maisha } & \text { ya } & \text { chuoni } & \text { na } & \text { adhabu zake zote } \\ \text { SM1-know } & \text { 6.life } & \text { 6.Assoc } & \text { 7.college } & \text { like } & \text { 10.torment 10.its } \\ \text { 10.all } & & & \end{array}$

'I know college life and all its torments'

\begin{tabular}{|c|c|c|c|c|c|}
\hline$M-s i b a$ & hии & $m-k u b w a$ & $n i$ & kama & radi. \\
\hline 1-bereavement & 3.this & 1-big & be & like & thunder \\
\hline
\end{tabular}

The examples in (24-28) demonstrate various complex noun phrases in Swahili. While in (24) the quantifier lolote 'any' and an adjective baya 'bad' co-occur, example (25) demonstrates an adjective kidogo 'small' and a genitive construction cha ngozi 'of leather' co-occurring in a noun phrase. These cases represent the co-occurrence of elements in modification constituent because once co-occurrence with demonstratives and/or possessives will push these elements outside the adjacency of the lexical noun.

In example (26) the possessive zako 'your' co-occur adjacent to the lexical noun while a numeral mbili 'two' is found to the right edge of the noun phrase. Likewise, in (27) the possessive zake 'its' is adjacent to head-noun while a quantifier zote 'all' takes the right edge of the noun phrase. In example (28) the demonstrative huu 'this' precedes an adjective mkubwa 'big'. This the principle of head proximity warrants elements closer to the head noun to be determiners, then it follows that demonstratives and possessives formulate determinations in Swahili examples above.

However, it is also shown in the literature that many lexical entities formulate constituents in complex Bantu NPs. It is from data exemplified above that these elements include demonstratives, adjectives, possessives, quantifies, numerals and genitive (associative) constructions. Another element is the relative clause which is attested in many Bantu languages such as Matengo (Ndomba, 2006), Runyambo (Rugealira, 2007), Sukuma (Magashi, 2008), Bembe (Iori 2011), etc. Lusekelo (2009a) found that narratives tend to comprise NPs with these elements in Swahili language. 
At this juncture, I needed to examine the patterns of the tokens of NPs gathered from letters from Shaaban Robert. The statistical summary provided in (29) below reflects what is contained in the data.

\section{(29) Sequences}

i. $\mathrm{N}$ POSS

ii. $\mathrm{N}$ POSS

iii. $\mathrm{N}$ POSS

iv. $\mathrm{N}$ POSS

v. $\mathrm{N}$ DEM

vi. $\mathrm{N}$ QUANT

vii. $\mathrm{N}$ QUANT

viii. $\mathrm{N}$ ADJ

ix. $\mathrm{N}$ QUANT

x. N DEM

xi. N DEM

TOTAL

\section{Frequencies of use in texts}

QUANT 10

ASSOC 5

ADJ 3

NUM 2

ASSOC 2

REL 2

ADJ 2

ASSOC 1

ASSOC 2

ADJ 1

REL 1

Basic observations point towards the pattern that seems to suggest that freedom of word order is possible in Swahili. This is because there are so many patterns of occurrence of these elements around the lexical noun. Nonetheless, a close examination of the data above implies that possessives and demonstratives cannot be preceded by quantifiers, relative clauses, associative constructions, adjectives, numerals and quantifiers. This being the case, the head proximity principle satisfies the claim that both DEM and POSS are indeed utilised in the formulation of determinations in Swahili.

Regarding these developments, becomes plausible to argue that both demonstratives and possessives qualify for determination in Swahili NPs. The speaker can optto employ either the possessive or demonstrative in signaling definiteness and refentiality. It is also assumed that addressee obtains the proper referents based on the determiner used.

It is now clear that Swahili NPs vary with respect to their internal organisation. However, their complexity may not be fully provided using the tokens of data from letters of Shaaban Robert to Yusuf Ulenge. Nonetheless, findings indicate that evidence contrary to Rijkhoff (2002, p.24) who stated that 'in normal, unelicited speech, an NP will most frequently involve only two; maximally three constituents', and, in fact, four would be the maximum number of dependents gathered in written source for this study. Perhaps the cases provided below will justify this claim.

$\begin{array}{lllll}\text { Barua } & \text { zako } & \text { zote } & \text { tatu } & \text { zi-me-fik- } a \\ \text { 10.letter } 10 . \text { your } & 10 . \text { all } & \text { 10.three } & \text { SM10-PFV-arrive-FV } \\ \text { 'All three letters of yours arrived' } & \end{array}$

$\begin{array}{lllllll}\text {.. ya-li-yo-tangua } & \text { ma-shauri } & \text { yangu } & \text { yote } & \text { ya } & k u \text {-ja } & \text { huko } \\ \text { SM6-PST-REL6-stop } & \text { 6-plan } & 6 . m y & \text { 6.all } & \text { 6.ASSOC } & \text { INF-come } & \text { there } \\ \text { '... prevented all my plans of coming there' } & & & & \end{array}$


In example (30), the obtainable sequence as provided by Shaaban Robert is N » POSS » QUANT » NUM. In example (31), the sequence obtained is N » POSS » QUANT » ASSOC. Challenging the suggestion given by Rijkhoff (2002), these sequences demonstrate that three dependents may co-occur in a Swahili NP. It means that a noun phrase in the language may comprise four constituents.

In addition, these sequences maintain the findings that possessives function to delineate determinations in Swahili. This is because in these examples, the possessive occurs very close to the lexical nouns.

Given the analyses in the preceding parts of this paper, it is plausible to suggest the architecture of the Swahili DP using the phrase viatu vyako vidogo 'your small shoes'. In fact, the left-most part might be occupied by the nominal prefix $v i$-, which is traditional in Bantu languages (Katamba, 2003). The lexical-noun follows (viatu 'a pair of shoes), and its position at the bottom of the NP is traceable (Carstens 1991), as shown in (32). The other elements, i.e., an adjective vidogo 'small' tend to appear after the possessive, that is, vyako 'your'.

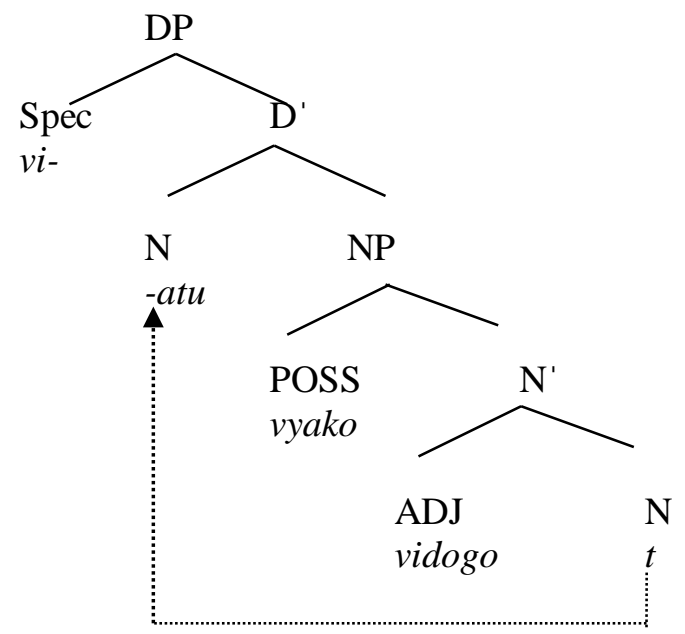

Alternatively, the noun phrase msiba huu mkubwa 'this big bereavement' has the nominal prefix $m$ - in the left-most part. The lexical-noun msiba 'bereavement' follows in hierarchy. Its original position was at the bottom of the NP is, as shown in (33). The demonstrative huu 'this' appears after an adjective mkubwa 'big'. 


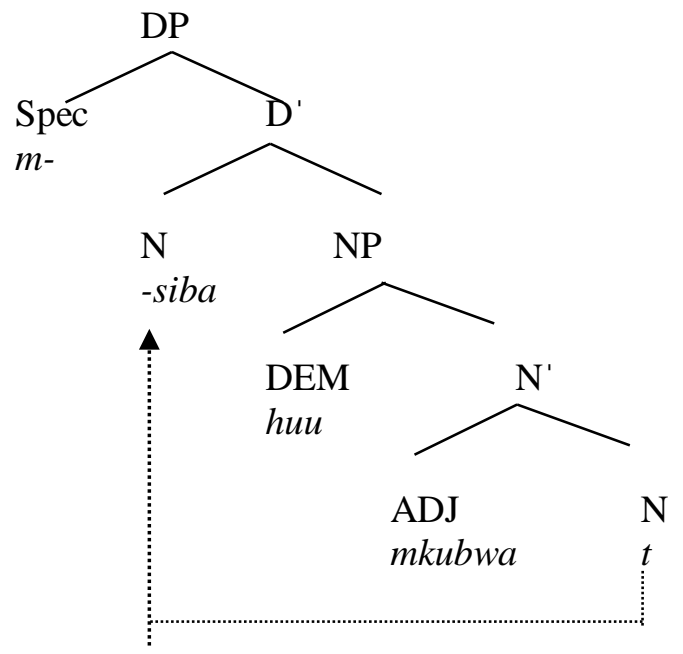

\section{Conclusion}

Since the existing research output for the structure of the noun phrase in Bantu languages maintains three questions, I articulated in this paper that the syntactic properties of lexical nouns in Swahili has a close relation to its functional projections which are associated with both concord in determiner phrases and agreement in inflectional phrases. I showed in the paper that the realisations of syntactic properties in Bantu noun phrases is not associated with use of pre-prefix which was previously suggested that it denotes discourse-based information about (in)definiteness. I showed that context of communication is crucial in deciding for the definite interpretations of bare nouns in Swahili.

In addition, I questioned in this paper the claim that definiteness is made possible through indication of phi-features in minimalist syntax by using the nominal prefix. Findings from Swahili texts point towards the fact that bare nouns receive either definite interpretation or indefinite reading depending on the context of communication. Therefore, the definiteindefinite distinction is not provided by physical linguistic materials but rather by discoursebased contexts. In the last, I discussed entities revolving around determination by means of demonstratives and possessives as supported by head proximity principle. I argued that even when a demonstrative and/or possessive is used, it is the context of communication which situates the specific referent rather than the lexical entities. Therefore, it is generally argued the in this paper that the choice between demonstratives and possessives in determinations of Swahili NPs is also context bound.

\section{References}

Abney, S. P. (1987). The English noun phrase in its sentential aspect. Cambridge, Mass.: MIT. (Doctoral dissertation).

Allen, A. (2014). Definiteness and specificity in Runyankore-Rukiga. Stellenbosch: Stellenbosch University. (Doctoral thesis).

Artemis, A., Haegeman, L., \& Stavrou, M. (2007). Noun phrase in the generative perspective. Berlin: Mouton de Gruyter.

Blommaert, J. (2013). State ideology and language in Tanzania. Second and revised edition. Tilburg papers in cultural studies, Tilburg University, paper 80. 
Bokamba, G. D. (1971). Specificity and definiteness in Dzamba. Studies in African Linguistics, 2. 217-38.

Bowern, C. (2008). Linguistic fieldwork: A practical guide. New York: Palgrave Macmillan.

Carstens, V. (1991). The morphology and syntax of determiner phrases in Kiswahili. California: University of California, CA. (Doctoral dissertation).

Carstens, V. (2008). DP in Bantu and Romance. In De Cat, Cécile \& Katherine Demuth (Eds.). The Bantu-Romance connection: A comparative investigation of verbal agreement, NPs and information structure, 131-165. Amsterdam: John Benjamins.

Chipeta, D. (2016). The analysis of Kisukuma determiner in its sentential aspect. Iringa: Ruaha Catholic University (MA dissertation).

Contini-Morava, E. (2000). Noun class as number in Swahili. In Contini-Morava, Ellen \& Yishai Tobin (eds.). Between grammar and lexicon, 3-30. Amsterdam: John Benjamins.

De Blois, K. F. (1970). The augment in the Bantu languages. Africana Linguistica IV. 87165.

Henderson, B. (2006). Multiple agreement, concord and case checking in Bantu. In Arasanyin, Olaoba F. \& Michael A. Pemberton (eds.). Selected proceedings of the 36th Annual Conference on African Linguistics, 60-65. Somerville, MA: Cascadilla Proceedings Project.

Hyman, L., \& Katamba, F. X. (1993). The augment in Luganda: Syntax or pragmatics? In Mchombo, Sam (ed.). Theoretical aspects of Bantu grammar, 209-256. Stanford: CSLI, Stanford University.

Jaffu, S. N. (2010). The structure of Chimakonde noun phrase. Dar es Salaam: University of Dar es Salaam. (MA dissertation).

Katamba, F. (2003). Bantu nominal morphology. In Nurse, Derek \& Gérard Philippson (eds.). The Bantu Languages, 103-120. London: Routledge.

Letsholo, R. (2004). Clausal and DP-internal agreement in Ikalanga. Studies in African Linguistics 33(1). 91-127.

Lusekelo, A. (2009a). The structure of the Swahili noun phrase: Evidence from fictional narratives. In Burger, Willie \& Marné Pienaar (eds.), Die tand van die tyd: Opstelle opgedra aan Jac Conradie, 45-60. Bloemfontein: Sun Press.

Lusekelo, A. (2009b). The structure of the Nyakyusa noun phrase. Nordic Journal of African Studies, 18 (4): 305-331.

Lusekelo, A. (2013). DP-internal and V-external Agreement Patterns in Bantu: Re-statement of the Facts on Eastern Bantu Languages. Journal of Linguistics and Language in Education 7(1). 19-47.

Magashi, S. (2008). Kisukuma noun phrase structure. Dar es Salaam: University of Dar es Salaam. (MA dissertation) 
Maho, J. (1999). A comparative study of Bantu noun classes. Gothenberg: Acta Universitatis Gothoburgensis.

Mojapelo, M. L. (2007). Definiteness in Northern Sotho. Stellenbosch: Stellenbosch University. (Doctoral thesis).

Mulokozi, M. M. (1974). Revolution and reaction in Swahili poetry. UTAFITI, 127-147.

Mulokozi, M. M. (ed.). (2002). Barua za Shaaban Robert 1931-1958. Dar es Salaam: Institute of Swahili Studies.

Ndomba, R. (2006). Samatengo noun phrase structure. Dar es Salaam: University of Dar es Salaam. (MA dissertation).

Petzell, M. (2008). The Kagulu language of Tanzania: Grammar, texts and vocabulary. Cologne: Rüdiger Köppe Verlag.

Rijkhoff, J. N. M. (1986). Word order universals revisited: The principle of head proximity. Belgian Journal of Linguistics 1. 95-125.

Rijkhoff, J. (2002). The noun phrase. London: Oxford University Press.

Rizzi, L. (1997). The fine structure of the left periphery. In Haegeman, Liliane (ed.), Elements of grammar, 281-337. Kluwer: Dordrecht.

Sarakikya, S. P. (2016). The X-bar theoretical account of the Kimeru noun phrase structure. Iringa: Ruaha Catholic University (MA dissertation).

Szabolczi, A. (1994). The noun phrase. In Kiefer, Ferenc \& Katalin É. Kiss (eds.). The syntactic structure of Hungarian, 179-275. Brill: Academic Press.

Van de Velde, M. (2005). The order of noun and demonstrative in Bantu. In Bostoen, Koen \& Jacky Maniacky (eds). Studies in African comparative linguistics with special focus on Bantu and Mande, 425-441. Tervuren: Royal Museum for Central Africa.

Vaux, B., \& Justin, C. (2003). Introduction to linguistic field methods. Muenchen: Lincom Europa.

Visser, M. (2010). Definiteness and specificity in Xhosa determiner phrase. In Legère, Karstens \& Christina Thornell (eds.), Bantu languages: Analysis, description and theory, 295-314. Köln: Rüdiger Köppe Verlag.

Zhukov, A. (2004). Old Swahili-Arabic script and the development of Swahili literary language. Sudanic Africa, 15. 1-15. 